\title{
História, república e fundaçāo da cidade de Florença em Coluccio Salutati, Leonardo Bruni e Maquiavel
}

History, republic, and the foundation of the city of Florence in Collucio Salutati, Leonardo Bruni and Machiavelli

Fabrina Magalhāes Pinto a

E-mail: fabrinamagalhaes@gmail.com https://orcid.org/0000-0001-5088-9125 [D

Luís Falcāo ${ }^{b}$

E-mail: luis.alves.falcao@gmail.com https://orcid.org/0000-0003-3785-626X D

a Universidade Federal Fluminense, Instituto de Ciências da Sociedade e Desenvolvimento Regional, Departamento de História, Campos dos Goytacazes, RJ, Brasil

b Universidade Federal Fluminense, Instituto de Ciências Humanas e Filosofia, Departamento de Ciência Política, Niterói, 


\section{RESUMO}

O artigo argumenta que a historiografia humanista e renascentista sobre as origens de Florença produziu, paulatinamente, rupturas com a visão medieval da fundação da cidade pelo Império Romano. Com Salutati, há a primeira declarada defesa da fundação pela República Romana, sustentada em monumentos históricos e textos antigos. Bruni acrescenta o fato de que, por legítima herdeira, Florença recepciona ainda a responsabilidade de levar glória e grandeza às demais províncias da península. Malgrado o contexto de guerra com Milão ser importantíssimo nas explicações dos textos desses humanistas, a continuidade do tema com Maquiavel prova que ele sobreviveu pela sua força teórica, ainda pouco explorada pela bibliografia especializada. Para ele, não se trata apenas de ligar as origens de uma cidade ao seu prestígio e função na contemporaneidade, mas o tema da fundação em si mesmo exige uma reflexão teórica. $O$ artigo apresenta esses marcos atento às inflexões e, sobretudo, aos aspectos teóricos de composição historiográfica.

\section{PALAVRAS-CHAVE}

Renascimento. Florença. Fundação.

\section{ABSTRACT}

This article argues that humanism and renaissance historiography about the origins of Florence caused gradual ruptures with the medieval idea of the city's foundation by the Roman Empire. Collucio Salutati introduces the first declared defense of the foundation by the Roman Republic, which is supported by historical monuments and ancient texts. Leonardo Bruni adds that, as a legitimate heritage, Florence also takes on the responsibility of bringing glory and greatness to the other provinces of the peninsula. Although the war with Milan is extremely important to explain the texts of these humanists, the continuity of the theme with Niccolò Machiavelli proves that the idea survived by its theoretical strength, even if less explored by the specialized bibliography than other themes. For Machiavelli, it is not just a matter of linking the origins of a city to its prestige and function in the contemporary times, the very foundation requires a theoretical reflection. This article presents these milestones and focuses on the inflections and, above all, the theoretical aspects of historiographic composition.

\section{KEYWORDS}

Renaissance. Florence. Republic. 


\section{İntroduçāo}

Pretende-se neste artigo destacar o tratamento dos humanistas cívicos sobre a questão da fundação da cidade de Florença - sobretudo os chanceleres da República Florentina, Coluccio Salutati, Leonardo Bruni e Maquiavel -, em seus textos políticos: a Invectiva contra Antonio Loschi, de Salutati, o Elogio da cidade de Florença e a História do povo florentino, de Bruni, bem como os Discursos de Maquiavel. O percurso por esses autores nos permite compreender algumas rupturas significativas com os valores políticos medievais, por meio, sobretudo, do desenvolvimento de uma retórica inflamada ${ }^{1}$ (que passa a ser muito comum nos escritos dos séculos XV e XVI) que ressaltava tanto a relevância da liberdade florentina quanto a sua vinculação com a Roma republicana. Afinal, se os ancestrais florentinos já defendiam com tanto ardor a liberdade, nada mais central que os cidadãos do Quattrocento também a defendessem frente às ameaças da invasão da cidade de Milão.

Para esses historiadores de inícios da modernidade, o uso de novas fontes antigas, de novos métodos no tratamento delas e uma nova interpretação sobre o passado reinventam a cidade, criando uma forte e legítima tradição republicana, livre e com profundo apreço pela participação cívica nos moldes ciceronianos.

Para esticar um pouco mais esse percurso no tempo, retornamos ao historiador medieval Giovanni Villani: tendo em vista que "são poucas e desordenadas as memórias sobre a cidade de Florença", ele, "cittadino di Firenze", escreve uma nova crônica para tratar desse assunto: a sua Nuova Cronica (1333?-1348). ${ }^{2}$

Como observa Quintiliano, a maioria dos retóricos romanos concorda que são três os gêneros da retórica: o deliberativo, o judiciário e o demonstrativo (ou epidíctico). Segundo ele, esse consenso se dava pelo fato de os retores aceitarem a tipologia originalmente proposta por Aristóteles, no livro I, capítulo III, de sua Retórica, no qual ele propõe que cada um desses gêneros tem um tempo e uma função que Ihes é apropriada. O deliberativo cuida das deliberações sobre o que é útil ou prejudicial à cidade, e seu tempo é o do porvir; o judiciário trata das acusações e defesas, e seu tempo é o passado; o demonstrativo trata dos elogios ou dos vitupérios, e seu tempo é o presente. É fato, porém, que os teóricos romanos têm muito pouco a dizer sobre esse tipo de discurso. Cf. Quintiliano (Institutio oratoria, III, VI, I). O caráter inflamado da retórica é, portanto, uma característica do gênero deliberativo, voltado para as assembleias e para a discussão pública, mesmo que na forma de um auditório "ideal". Sobre essas tipologias da retórica, ver também Molinié (1992) e Perelman (1976).

2 A Nuova Cronica, escrita por Giovanni Villani na primeira metade do século XIV e continuada, após a sua morte, por seu irmão Matteo e, após este, por seu sobrinho Fellipo, é um dos mais preciosos registros que nos chegaram sobre a vivência urbana medieval. Utilizamos neste artigo a seguinte versão: VILLANI, 1991. Sobre a datação inicial da Crônica, existe um longo debate do qual não poderemos entrar aqui. Para isso, ver Luiz (2014, p. 115-120). 
Este livro chama-se Nova Crônica, no qual se trata de feitos passados, especialmente da origem e início da cidade de Florença depois de tantas modificações que houve, e haverá, ao longo do tempo: começando sua compilação no ano de 1300 da encarnação de Jesus Cristo (VILLANI Nuova Cronica, 1991, Prólogo, I).

O florentino toma para si a responsabilidade de escrever a história de Florença a exemplo de grandes historiadores de Roma - como Salústio, Lucano, Valério Máximo e Tito Lívio -, reconhecendo-se também como alguém que partilha do mesmo ofício daqueles de outrora. Também de Roma é a filiação de Florença, a quem delega o atributo de ser a continuação de Roma: "filha e criatura de Roma" (VILLANI Nuova Cronica, 1991, IX, p. 36). Villani é, no entanto, um historiador cristão que submete não apenas a sua crônica, mas também a própria história à vontade de Deus, "por tanto tempo quanto for o prazer de Deus" (VILLANI Nuova Cronica, 1991, IX, p. 36). Assim, por diversas vezes, realça a relação do pecado e da moralidade com os eventos históricos, afirmando que o excesso desses leva à ruína das cidades, e que os acontecimentos históricos são diretamente influenciados pela Providência. Ainda que a Providência não se sobreponha ao livre-arbítrio dos homens, ela opera no sentido de puni-los em suas más ações e de recompensá-los pelas boas.

Fortemente marcado pela tradição medieval, o autor destaca a necessidade de se relembrarem os fatos que marcaram a história da comuna para que seus contemporâneos pudessem compreender que, já na primeira metade do século XIV, Florença vivia um tempo especial, de grandeza e potência (tanto militar e civil quanto mercantil). Por essa razão Villani escreve em língua vulgar³, no dialeto toscano, e não em latim).

Tanto mais que para os nossos antigos florentinos poucas e desordenadas memórias encontramos dos feitos passados de nossa cidade de Florença, por negligência nossa, ou porque no tempo em que Átila, o Flagelo de Deus, a destruiu, se perderam os manuscritos, eu Giovanni, cidadão de Florença, considerando a nobreza e grandeza de nossa cidade nos tempos atuais, a mim parece conveniente contar e relembrar a memória da origem e começo de tão famosa cidade, e das suas mudanças afortunadas e desafortunadas, de seus fatos passados (VILLANI Nuova Cronica, 1991, I, p. 1).

${ }^{3}$ Diz Villani: "e eu fielmente narro esse livro em língua vulgar, para que os leigos e os analfabetos possam dele tirar deleite e proveito, e se, em alguma parte, houver erro, deixo a correção para os mais sábios" (VILLANI Nuova Cronica, 1991, I, p. 1). 
O cronista escreve uma história de Florença que é ao mesmo tempo exemplar e "luz da verdade", pois recupera as memórias perdidas e mantém em registro as novas, "para dar matéria aos nossos sucessores para que estes não sejam negligentes com a memória das notáveis coisas que aconteceram no tempo, e para dar exemplo àqueles que devem sustentar com forte ânimo a nossa república em tempos de adversidade" (VILLANI Nuova Cronica, 1991, I, p. 2). Assim, a nobreza e a virtude dos progenitores romanos constituem a premissa central para a celebração da cidade. Esse aspecto certamente não é novo nas crônicas anteriores, mas no contexto florentino assume um peso particular, e Villani o sublinha com singular evidência. Ao tratar então da história da fundação florentina, ele começa com o conflito entre os nobres e virtuosos romanos e os rudes fiesolanos (VILLANI Nuova Cronica, 1991, II, p. 1), considerando que a cidade foi criada no período imperial, após o envio de tropas por César para punir os habitantes de Fiésole, por terem apoiado Catilina em sua revolta. Nessa Florença original, reta e governada ao modo de Roma, isto é, "por dois cônsules e pelos senadores" (VILLANI Nuova Cronica, 1991, IV, p. 3), o autor coloca em evidência a unidade dos cidadãos, mas, em nenhum momento (ainda que a riqueza e a magnificência de Florença sejam destacadas em várias partes), o expansionismo territorial na região da Toscana é exaltado. Segundo Francesca Klein (1980, p. 311-336), "a prosperidade é um valor absoluto, jamais concebido como ponto de partida para agregação territorial", pois, para Villani, "a dimensão municipal continuava a ser o fundamento e o limite extremo da magnificência citadina". Já Salutati e Bruni colocam o acento sobre a fundação da cidade no período republicano (em oposição à tradição anterior). Dentre os dois, é em Bruni que teremos o lance mais significativo: o humanista vê a posição de Florença não mais como centro de gravitação do microcosmos comunal, mas como única cidade capaz de expandir suas instituições e o governo republicano para toda a península itálica.

\section{A Invectiva contra Antonio Loschi, de Salutati ${ }^{4}$}

A Invectiva contra Antonio Loschi, de Salutati, é uma resposta a um panfleto de 1399 escrito por Loschi - Invectiva contra os florentinos - na qual o chanceler

\footnotetext{
O humanista e chanceler florentino Coluccio Salutati (1331-1406), escreveu, entre outros trabalhos, a Invectiva contra Antonio Loschi de Vicenza, de 1403, em que a sua maior preocupação é a defesa da cidade contra as acusações de Gian Galeazzo Visconti, duque de Milão, e sua tradicional legitimidade. Não podemos esquecer a tese de Hans Baron (1955), segundo a qual o motivo fundamental do conflito estava não apenas no expansionismo unilateral dos Visconti, mas também no embate entre dois expansionismos: o milanês e o florentino (podemos nos lembrar, por exemplo, da aquisição de Arezzo, em 1384, e da rápida evolução e radicalidade do projeto). Para a leitura completa desse texto, ver a edição organizada por Baldassari (SALUTATI 2014), "Invectiva Against Antonio Loschi".
} 
florentino condena ferozmente seu adversário por pronunciar uma série de ofensas à cidade de Florença, que, segundo ele, são infundadas, não podem ser comprovadas e foram escritas por uma "estultíssima besta". Diante de tais absurdos, Salutati, que teria recebido o texto por intermédio de Pietro Turqui, envia sua contestação em 1403, e inaugura um dos tópicos fundamentais do humanismo cívico: a defesa da liberdade florentina contra a tirania do governo de Milão, representada por Loschi.

Hans Baron (1955) já sublinhou a importância do momento no qual foi escrita a Invectiva e como a ameaça do senhor de Milão foi uma experiência intensa para os florentinos, tendo em vista que os seus exércitos estavam já nas proximidades da cidade. Nesse momento, a retórica é posta à disposição da enunciação de uma teoria política que pretendia ser adequada a toda cidade florentina. Afastando-se da retórica medieval e dos dictatores medievais, os discursos do Quattrocento seguem os passos tradicionais em uma forma bem construída: inventio (descoberta do material), dispositio (organização do material), elocutio (a formulação), memoria e pronuntiatio, como um instrumento adequado para se agir na cidade 5 . A retórica, sobretudo ciceroniana, passa a ser vista em inícios da Modernidade como um elemento essencial na vida ativa, e um dos primeiros exemplos desse retorno são os combates travados pelos humanistas em defesa dos valores das suas cidades ou de seus senhores, como é o caso da Invectiva contra os florentinos. Assim, Salutati se propõe a responder passo a passo às críticas de seu interlocutor, condenando-o, já no início da carta, por "sustentar o nome romano e a declarar a sua filiação à Roma". "Oh, quão grande é a vossa impudência". E continua:

"Veremos", tu escreves, e de fato tu viste, vês e verás ainda mais constância romana e tenacidade dos florentinos na defesa da doce liberdade, [que, como foi dito por Esopo é] "o bem celestial excedendo todas as riquezas do mundo". Em toda Itália e em qualquer outro lugar, há uma liberdade mais livre e mais intacta que a liberdade desfrutada pelos florentinos, uma liberdade mais elevada ou que se possa comparar à nossa? (SALUTATI Invectiva, 2014, § 20).

Mencionar a liberdade como uma característica estabelecida do regime florentino era um lugar-comum usado em diversos textos do século XIV, tanto nos manuais de

${ }^{5}$ Não teremos meios, neste artigo, de explorar os usos da retórica feitos pelos dictatores medievais, por exemplo. Dessa forma, para compreender melhor como a retórica renascentista ganha em complexidade em relação aos modos anteriores, os estudos de James Murphy (1983 e 1998) podem ser de grande valia nesse sentido. 
retórica quanto nos discursos cívicos pronunciados em diversas ocasiões. Nesse sentido, têm razão intérpretes como Skinner (1996) e Hankins (1995 e 2000), que não veem nisso senão a afirmação de uma tradição já consolidada no período medieval, ainda que esse combate ganhe maior tensão quando defendido por oradores tão hábeis. Contudo, o apelo à liberdade ganha outra dimensão quando associado a temáticas como, por exemplo, aquela da fundação de Florença atrelada à Roma do auge de seu período republicano. Esse seria o lance - para usar o termo do próprio Skinner - em relação à tradição política anterior.

Na Invectiva, Loschi nega que os florentinos sejam descendentes da estirpe romana, e Salutati, diante de tal acusação, pede a seu adversário que mostre onde ele encontrou as provas para tal afirmação e o questiona:

Já que parece negar as origens romanas do povo florentino, dize-me, por favor, onde encontraste opinião contrária? Por que invejas o que toda a Itália, exceto tu, reconhece em nós, o que ninguém, salvo tu, besta imunda, alguma vez duvidou? Por que ser tão invejoso daquilo que a cidade de Roma e os imperadores romanos em nenhum momento negaram, de tal forma que ainda hoje eles nos chamam e nos consideram seus filhos, carne de sua carne e ossos de seus ossos, fonte de orgulho e honra para seu nome? (SALUTATI Invectiva, 2014, § 22).

Para se contrapor a tais delírios, o chanceler promete oferecer a seus leitores a correta percepção sobre os fatos e as evidências históricas que comprovam a sua tese. Comparando a dificuldade de se narrarem acontecimentos tão antigos como a fundação de Florença e de Roma, Salutati começa apresentando indícios materiais da fundação de sua cidade pelos romanos, no período republicano, a partir da arquitetura e dos monumentos dela, em uma espécie de pesquisa arqueológica, que reaparecerá em outras obras de humanistas florentinos, como no Elogio à cidade de Florença e na História do povo florentino, de Leonardo Bruni. Como prova de sua tese, indica que há na cidade um Capitólio, e próximo dele, um Fórum; há um anfiteatro, as termas, "um importante templo dedicado a Marte, pai do povo romano" (SALUTATI Invectiva, 2014, $\S 24$ ); há os arcos, as torres redondas, as ruínas do portão (com claro estilo romano, segundo o autor), os vestígios de aquedutos e ainda uma estátua equestre de Marte, situada ao lado da Ponte Vecchio (que, no entanto, não sobreviveu devido às fortes enchentes que destruíram 3 outras pontes, mas que muitos - diz Salutati - ainda hoje dela se recordam). 
Levando em conta todos esses resquícios romanos, esses nomes romanos, a imitação de costumes romanos e a proteção de uma tradição famosa ainda em voga, quem ousaria dizer que os fundadores disso tudo seriam outros senão os romanos? [...] Não me espanta em nada, havendo tanta evidência para isso, que haja uma tradição intacta e inquebrável de que Florença tenha sido fundada pelos romanos e não pelos fiesolanos, que eram notoriamente hostis aos romanos. Lemos que na Guerra Social, Fiésole e outras cidades foram destruídas. Em resumo, é um absurdo duvidar de que Florença tenha sido construída pelos romanos (SALUTATI Invectiva, 2014, § 25).

Esses são vestígios imateriais da origem romana, alguns deles já presentes na Nuova Cronica de Giovanni Villani. Mas, destaca Salutati, indo além, os vestígios encontram também respaldo nas obras de autores romanos. A fonte central é Salústio, mais precisamente a Guerra de Catilina (28.4), em que já aparece a menção às colônias fundadas por Sila como defesa contra os fiesolanos.

De fato, lemos no confiável historiador Salústio que Lúcio Catilina enviou Caio Mânlio à Fiésole para recrutar um exército, o que ele fez ao "inflamar a gente comum, desejosa de revolta por causa de sua pobreza e dos muitos prejuízos sofridos, tendo perdido suas terras e pertences sob o regime de Sula; além disso, arregimentou ladrões, do tipo que havia naquela região em grande número, e não poucos membros das colônias de Sula, que já não podiam mais sustentar sua libido e sua luxúria com ganhos de roubos". Desse modo, ele reuniu um grande exército (SALUTATI Invectiva, 2014, § 26).

Salutati fundamenta essa nova versão a respeito da ascendência romana e republicana de Florença na informação fornecida por Salústio sobre a fundação da cidade pelos veteranos de Sila, entendendo que esse período da ditadura ainda se situa na república. Ele promove, pois, modificações bastante relevantes no campo da narrativa histórica (tanto com uma nova seleção e uso mais marcante das fontes antigas quanto na seleção dos materiais e documentos) e, em relação ao conteúdo, abandona a versão da fundação cesariana, defendida por Villanni, para estabelecer uma ideia de hereditariedade da Roma republicana, fazendo de Florença sua continuadora. Essa continuidade é justificada por meio da defesa da liberdade, característica das repúblicas.

O humanista endossa o argumento desenvolvido não apenas por Salústio, mas também por Cícero, em suas Catilinárias, evidência cabal de um novo paradigma 
historiográfico cuja legitimidade se assenta nos antigos 6 . Como negar, a partir dessas renomadas fontes, que os romanos fundaram colônias no território de Fiésole? Caberia a Loschi dizer "onde mais, além de Florença, eles instalariam aquelas colônias, tão próximas dos romanos em seus nomes, modos de construção, características e sob a égide de Marte?" (SALUTATI Invectiva, 2014, § 27).

Por que gastar tanta tinta para provar a origem do povo florentino é relevante? Primeiro porque o clamor pela liberdade move os florentinos desde tempos remotos, e, nisso, "a tradição republicana evocada por Salutati sugere que a relação com o passado possui uma significação que os autores medievais estavam longe de suspeitar" (BIGNOTTO 2001, p. 96). Nesse ponto, cabe chamar atenção para o caráter inovador do chanceler, posto que a liberdade primitiva dos florentinos torna-se imediatamente uma garantia, ainda que retórica, mas enraizada na fala discursiva, de que ela pode e deve ser retomada, mesmo contra os mais fortes adversários, seja a Igreja, seja Milão.

Como vimos até aqui, Salutati rompe com a tradição de vinculação de Florença com um passado imperial de Roma, usando claros recursos retóricos para dar à cidade um passado republicano e solidez à tese da sua origem livre, fundando assim um novo modelo que irá perpassar vários autores até Maquiavel. Contudo, mantém de seu predecessor a desvinculação da cidade com o expansionismo na Toscana. Leonardo Bruni, humanista, historiador e chanceler florentino, retoma de Salutati a questão da fundação como um ponto central, tanto em seu Elogio da cidade de Florença quanto em sua História do povo florentino.

${ }^{6}$ Sobre a importância de Cícero e sobre o lugar da retórica ciceroniana na gênese do humanismo, ver Garin (1969), Kristeller (1962), Fumarolli (1994), Galand-Hallyn (1999) e Witt (2000). 


\section{Leonardo Bruni ${ }^{7}$ e a fundaçāo}

Tanto a Invectiva quanto a Laudatio Florentinae urbis (Elogio da cidade de Florença) ${ }^{8}$ foram concebidas no mesmo contexto histórico: pouco após a morte do duque de Milão, Giangaleazzo Visconti, em 1402, quando a tirania milanesa representava ameaça à sobrevivência da cidade florentina9 ${ }^{9}$. Em trecho significativo, escreve Bruni:

Como diz Cícero, "sou da opinião de que devemos começar do princípio". De onde, portanto, se origina este povo? Quais foram seus ancestrais? Por quais mortais esta ilustre cidade foi fundada? Reconhecei, florentinos, reconhecei vossa estirpe e vossa linhagem! Considerai que de todas as gentes sois os mais ilustres! Os outros povos têm como ancestrais refugiados ou banidos de suas pátrias, camponeses, imigrantes obscuros ou fundadores desconhecidos. Os vossos fundadores, entretanto, foram os romanos, conquistadores e senhores de todo o orbe terrestre. Ó, Deus imortal, foram conferidas tantas coisas boas a esta única cidade de tal modo que tudo parece ter contribuído para sua beleza. [...] De primeira importância é: os florentinos têm sua origem no povo romano! Que outra nação no mundo inteiro foi mais ilustre, mais poderosa, que mais se destacou em todas as virtudes que a romana? [...] De fato, se buscas nobreza entre os fundadores, não encontrarás ninguém mais nobre no mundo inteiro que o povo Romano. Se procuras riqueza, ninguém mais rico; se procuras grandeza e magnificência, ninguém mais excelente nem mais glorioso; se procuras extensão de domínio, nada do lado de cá do oceano deixou de se curvar às armas e ao poder de Roma. Desse modo, Florentinos, a vós pertence por

\footnotetext{
Leonardo Bruni (1370?- 1444), discípulo de Salutati, escreveu a Laudatio Florentinae urbis (14031404) e a História do povo florentino (1417), traduziu a Política de Aristóteles e outros clássicos antigos, foi secretário pontificial (1405) e chanceler de Florença (1406-1411 e 1427-1444). Para uma biografia completa do humanista, bem como a relação de todas as suas obras, ver Hankins (2012) e Vasoli (1972).

\begin{abstract}
${ }^{8}$ A Laudatio Florentine Urbis é o primeiro texto importante de Bruni. Após ter conhecido um largo sucesso na primeira metade do Quattrocento, esse trabalho de juventude cai no esquecimento até fins do século XIX. Baron (1955 e 1968) é um dos primeiros autores a ressaltar a importância das suas obras para os estudos referentes ao humanismo cívico e publicá-la, contra a opinião tradicional que via a Laudatio apenas como um elegante exercício retórico e uma imitação do Panatenaico, de Elio Aristides. Entre as principais traduções da Laudatio citamos: Baron (LEONARDO BRUNI ARETINO 1968, p. 232-63); Paolo Viti (LEONARDO BRUNI ARETINO 1996, p. 568-647) e a edição bilíngue latim-francês por BernardPradelle (LEONARDO BRUNI ARETINO 2008, p. 205-301). Estamos utilizando aqui a edição bilíngue latim-português da Laudatio publicada na Revista Morus e organizada por Fabrina Pinto e Alexander Carvalho. Dito isso, todas as referências e citações do texto serão retiradas desta versão. Cf. LEONARDO BRUNI ARETINO 2016.
\end{abstract}

9 A Laudatio vem sendo interpretada ao longo das últimas décadas basicamente de duas formas: a primeira, como texto fundador do humanismo civil, como defende Hans Baron (1968), e a segunda, como obra exclusivamente retórica, como postula Hankins (1995, p. 309-338). 
hereditariedade o direito de domínio sobre todo o orbe terrestre e a posse de tudo que outrora fora de vossos pais (LEONARDO BRUNI ARETINO Laudatio, 2016, § 30-31).

Florença foi fundada, portanto, antes que César ou Antônio viessem a acabar com a liberdade de Roma (LEONARDO BRUNI ARETINO Laudatio, 2016, § 33-35), passando a relatar na sequência todos os males que os tiranos fizeram à república (LEONARDO BRUNI ARETINO Laudatio, 2016, § 44).

Não se pode deixar de ressaltar que essa questão sobre a origem romana do povo florentino é, diga-se, bastante original tanto em relação ao modelo grego de Aristides, em que Bruni se baseia, quanto em relação aos elogios medievais (BARON 1968, p. 232-263; BERNARD-PRADELLE 2000, p. 355-387; PINTO 2017, p. 163-186). Aqui o humanista retoma a discussão já iniciada por Salutati. Tal temática passa a ser um objeto constante do republicanismo florentino - sendo visível no Diálogo a Pier Paulo Vergerio e na História do Povo Florentino de Bruni - que retorna em autores como Maquiavel, Guicciardini e Giannotti. Não é demais sublinhar que esse tema históricoarqueológico apresenta uma forte conotação política e ideológica, não sendo por acaso que Bruni afirma, contra todas as outras teses e tradições, a ideia de que Florença tenha sido fundada como colônia romana ainda no tempo em que vigorava a liberdade republicana, portanto apenas essa cidade toscana poderia proclamar-se legítima herdeira da tradição romana e, por isso, manter o mesmo status político de cidadania desfrutada pelos habitantes de Roma.

Uma evidência importante que diferencia uma colônia republicana de uma submissa ao império é que, segundo Bruni, os imperadores repudiavam os valores caudatários da república. Assim, segundo Vasoli, o aspecto histórico mais interessante da afirmação dessa tese contraposta à historiografia medieval:

consiste no espírito anti-imperial que a inspira; no modo pelo qual Bruni abandona decisivamente o mito medieval da romanidade imperial para dedicar-se a uma visão da história de Roma estritamente 'cívica' e 'republicana' [...]. Na Laudatio, a polêmica anti-imperial é agora estritamente ligada à defesa da particular função histórica de Florença, e há um precioso intento propagandístico (VASOLI 1961-1962, p. 10-11). 
Ao final dessa parte do texto, Bruni introduz, assim como Elio Aristides ${ }^{10}$, as ações pacíficas e virtuosas que ressaltam a beneficentia de Florença (LEONARDO BRUNI ARETINO Laudatio, 2016, § 49-74), exata transposição da philantropia ateniense. Essa benevolência, passada e atual, é ilustrada por atos particulares dos cidadãos, sendo clara a alusão ao sofista grego, que trata deste ponto extensamente no Panatenaico, louvando a grandeza dos atenienses na Guerra do Peloponeso e nas guerras persas. Bruni mantém esse argumento de Aristides para defender a sua tese de que Florença - tal como Atenas -, ao conquistar outros povos e cidades, tratá-los-ia com filantropia e, somado a isso, também levaria até eles a sua cultura e a racionalidade de suas instituições políticas para as outras repúblicas da península itálica (PINTO 2017, p. 163-187). Ademais, tal como Roma, levaria aos seus descendentes a liberdade e a participação cívica.

Destaca-se, portanto, a associação entre o argumento da herança romana de Florença e o seu direito de conquista. Se a Florença pertence "por hereditariedade o direito de domínio sobre todo o orbe terrestre e a posse de tudo que outrora fora de vossos pais" (LEONARDO BRUNI ARETINO Laudatio, 2016, § 31), ela também teria o mesmo direito à expansão e à conquista de outras cidades. Sendo assim, todas as guerras seriam justas porque defenderiam a causa republicana e a reconquista dos territórios perdidos no passado medieval. A escolha de Bruni em alterar o argumento da fundação da cidade o permite justificar a guerra contra o imperador Henrique VII e a defesa da cidade contra o seu assédio até os recentes conflitos iniciados com Milão ${ }^{11}$ (VASOLI 1961-1962, p. 11). Assim é forjada na Laudatio uma ideia que ganhará cada vez mais amplitude na História do povo florentino: a hegemonia justa e quase natural de Florença sobre o resto da Itália.

\footnotetext{
10 Para Aristides (Panatenaico, 1987, § 54), Atenas é a cidade ideal para acolher os refugiados e exilados, "pois esta cidade, desde o princípio, se ofereceu ela mesma como patrimônio para os que estavam em necessidade". Essa discussão se estende ainda pelos capítulos 55 a 74, nos quais o autor explora o tema da benevolência ateniense em acolher e admitir os necessitados, bem como torná-los partícipes de seu território, de suas leis e de sua constituição. Da benevolência de seus cidadãos e da sua linhagem divina, desenvolve-se todo o argumento. "Como não será consistente enviar enxames de colônias e povoar a terra?" (ARISTIDES Panatenaico, 1987, § 74).
}

${ }^{11}$ Sobre os primeiros conflitos com os milaneses, ver, sobretudo, Najemay (2014, p. 238-251). 
No livro I da História do povo florentino ${ }^{12}$, a exaltação da liberdade republicana e a condenação do regime imperial como decadência política, moral e intelectual permanecem quase inalterados, mas o período de Sila já não é mais apresentado como um período áureo da história romana. Em pouco mais de uma década, Bruni pôde tanto ter ampliado o seu conhecimento histórico, maturado a sua reflexão, quanto, sobretudo, ter eliminado alguns exageros retóricos presentes na Laudatio, perfeitamente condizentes com o gênero literário do elogio, em que é possível amplificar ou mesmo omitir fatos históricos. Nossa hipótese é de que o olhar bastante favorável ao período silano presente na Laudatio foi atenuado ou mesmo eliminado na História após uma leitura mais atenta de Cícero e de Salústio, o historiador latino que, bem no início da sua Conjuração de Catilina, coloca como marco para a decadência política e moral de Roma justamente a destruição de Cartago.

\begin{abstract}
Ora, quando a república pelo trabalho e pela justiça prosperou, grandes reis foram submetidos pela guerra, nações bárbaras e grandes povos subjugados pela força, Cartago, concorrente do povo romano, destruída desde os seus fundamentos; quando todos os mares e terras se abriam, eis a fortuna a se por em cólera e a tudo se confundir. Aqueles que tinham, sem dificuldade, suportado fadigas, riscos e situações críticas e penosas, a esses a paz, as riquezas, coisas por sinal desejáveis, Ihes serviram de peso e aflição. Cresceu, primeiro, a ambição do dinheiro, depois a do poder; elas foram a centelha de todos os males (SALÚSTIO Catilina, 1990, p. 10).
\end{abstract}

O general Sila, investido pelo poder e pelas armas, teria então acelerado esse processo, marcando o triunfo da avidez e da ferocidade, "pois puseram-se todos a roubar e a pilhar, uns a cobiçar a casa, outros as terras de seus inimigos (SALÚSTIO Catilina, 1990, p. 11). Assim, uma leitura mais atenta de Cícero e de Salústio mostrava os soldados silanos, os pretensos fundadores de Firenze, como ótimos cidadãos e corajosos em sua origem, mas depois, enriquecidos com o espólio no exército de Sila, acostumaram-se ao luxo e ao desperdício e, por isso, viviam carregados de dívidas. Esses colonos arruinados seriam matéria inflamável para a conjuração de Catilina.

\footnotetext{
2 Retornando a Florença entre fins de 1414 e inícios de 1415, Bruni pôs-se a escrever uma história da república florentina. O primeiro volume aparece em 1416, e os demais foram redigidos ao longo de três décadas. O humanista compõe nove volumes, deixando o décimo inacabado no ano da sua morte, em 1444. A narrativa bruniana percorre quatorze séculos da história de Florença, desde a fundação romana até a morte de Giangaleazzo Visconti, em 1402. Sobre essa obra, ver FUBINI (1980, p. 403-448); WILCOX (1969, p. 3-5). No Brasil, sobre a História bruniana e suas influências, ver o livro pioneiro de Murari Pires (2007, p. 85-108). Para a História do Povo Florentino de Bruni, temos a tradução realizada por James Hankins (LEONARDO BRUNI ARETINO 2001, 2004, 2007), organizada em 3 volumes e a versão organizada por Emilio Santini e Carmini di Pietro (LEONARDO BRUNI ARETINO 1926).
} 
Como se poderia nesse contexto idealizar a virtù republicana? Na Conjuração, Salústio apresenta o personagem principal da história como exemplo da ausência de virtù, já César e Catão são os casos exemplares, contrários àquele.

Bruni, ainda no livro I, não busca encontrar justificação econômica ou política para a revolta da campanha etrusca, entretanto, atenua a condenação dos fundadores de Florença mostrando como a doença catilinária foi um mal passageiro. Mais interessante aqui é perceber como o humanista relata a suspeita sobre a participação de César na conjuração de Catilina sem excluir sua validade, como faz Salústio, mas, na verdade, quase insinuando que a acusação está certa. "A suspeita recaiu também sobre César, que se tornou, posteriormente, ditador, embora nesta época ele não tivesse nenhum cargo público, estava assolado com dívidas e sedento por uma revolução" (LEONARDO BRUNI ARETINO História, 2001, L. 1, p. 7). Percebe-se quase uma ponta daquele anticesarismo republicano no qual Bruni esteve imerso em boa parte das suas obras anteriores (LEONARDO BRUNI ARETINO Laudatio, 2016 § 34), sem as hesitações de Coluccio Salutati. O que pode ter então interessado Bruni na história de Salústio não deve ter sido tanto a narrativa da rebelião, mas a breve introdução que contém um esboço da história ético-política de Roma e, particularmente, os primeiros dois capítulos, que contêm a passagem do regime monárquico àquele republicano e a idealização da Roma arcaica, caracteristicamente ciceroniana. Compreender a razão e o sentido desse interesse significa penetrar no centro e na gênese do pensamento político de Bruni.

Como nos diz Salústio, quando os colonos romanos são liberados do luxo e da cobiça estimulados por Catilina, há novamente um florescimento da virtude, tal como existira na Roma republicana ${ }^{13}$. As virtudes cultivadas são próximas nos dois historiadores: civil e militar; em Salústio, a primeira depende da segunda, já no caso de Bruni, a segunda depende da primeira. A fim de evitar uma abordagem excessivamente esquemática, é necessário ter claro que para o historiador florentino a primazia da boa organização da cidade unida à participação cívica dos cidadãos remete à excelência militar. Ainda que para os dois autores os termos não sejam fundamentalmente diferentes, o civil e o militar, o fato é que no Quattrocento italiano já se desenhava uma forma de convívio público na qual se podia perscrutar a liberdade do cidadão e da cidade. Nesse sentido, o militarismo não tem um fim em si nem carrega consigo uma justificativa moral para

Como vemos nessas duas passagens da História, de Bruni (LEONARDO BRUNI ARETINO História, 2001, I, p. 9): "Desse modo, tendo a cidade emendado seus rumos, tornou-se mais robusta e os imigrantes frequentes [...]. Temendo dever dinheiro, diligentemente passaram a inspecionar e usar com cautela (suas coisas), a usar de frugalidade e parcimônia, cultivar a sobriedade, disciplina com as coisas domésticas, considerando o luxo e a prodigalidade como via para perdição, isso eles mesmos faziam e passaram a educar assim seus filhos". 
a expansão, muito menos é, isoladamente, o ponto de ancoragem da boa ordenação republicana. Por outro lado, uma cidade que não se defende se torna presa fácil do mais fraco dos inimigos. A perspectiva de Bruni dessa dimensão militarizada da cidadania, ainda que incorra em alguma glória dos antigos, é refletida antes de mais nada na dimensão cívica e política do espaço público da cidade.

Contudo, o ponto que gostaríamos de ressaltar é ainda outro. Ao início do livro II de sua História, Bruni quer que admiremos o florescimento de Florença, o novo ímpeto de seu povo após a morte de Federico II e a consolidação do regime popular sob novas instituições. Acreditamos que, ao delinear esse processo ético-político, o humanista se deixa guiar pelo entusiasmo com o qual Salústio descreve o impulso do povo romano ao liberar-se do regime monárquico.

Mas naquele tempo todos começaram a levantar suas aspirações e a mostrar sua engenhosidade. De fato, aos reis são mais suspeitos os bons que os maus, e sempre inspiraram seu medo a virtude alheia. Mas, tendo conquistado a liberdade, é incrível a velocidade com que a cidade cresceu: tanto era o desejo de glória [...]. Assim na paz e na guerra se cultivarão os bons costumes... Por meio dessas duas artes, audácia na guerra, quando da paz, advinha a equidade (justiça), cuidavam de si e do estado [res publica] (SALÚSTIO Catilina, 1990, p. 7 e 9). ${ }^{14}$

Sobre o mesmo ponto, diz Bruni:

A partir desses indícios, é admirável de dizer quanto cresceu a força do povo. As pessoas que pouco antes eram servis ao príncipe ou a seus apoiadores, agora, depois de terem experimentado a doçura da liberdade, voltam todas as suas forças para elevarem a si mesmos e merecer respeito entre os seus. Desse modo desenvolveram prudência e indústria doméstica, coragem e armas no estrangeiro (BRUNI História, 2004, L. 2, p. 27).

É importante destacar a concordância dos autores em um princípio fundamental: o regime tirânico e nobiliário acaba com o talento e intensifica a pobreza, enquanto o regime republicano ou popular oferece plenas condições para o estabelecimento das virtudes. O regime da liberdade é, antes de tudo, o regime em que a capacidade dos cidadãos pode ascender, tendo em vista que, nesse estado não monárquico e não

O conteúdo citado foi comparado com a versão bilíngue, editada por John Ramsay, cf. SALLUST 2003. 
aristocrático, a civilidade (ou, se preferirmos, a participação cívica) floresce melhor. Naturalmente, os mesmos anseios se fazem presentes no livro I, no qual Bruni (História, 2001, L. I, p. 14) condena a passagem da República ao Império Romano. A condenação do regime imperial certamente se origina em outros historiadores latinos, como Tácito, por exemplo. Contudo, é da Conjuração a Catilina que parte a menção bruniana que está presente em todo o seu humanismo cívico.

Se, portanto, na Laudatio, que segue muito proximamente os argumentos de Elio Aristides, a presença de Salústio é rara, mencionada, segundo Bernard-Pradelle, apenas no capítulo $65^{15}$, em que o humanista destaca que tratará de todas as conquistas e glórias da cidade de Florença em obra própria, na História a presença de Salústio se faz mais presente, reforçando tanto o argumento da liberdade republicana (frente às aspirações do Império) quanto a ideia de que o princípio do regime popular é superior a todos os outros porque permite aos cidadãos a possibilidade de aspirar a cargos públicos, fato esse que estimula as capacidades e as virtudes deles.

\section{Maquiavel e a fundaçāo}

Dentre as rupturas empreendidas por Maquiavel em relação ao pensamento político e particularmente com relação ao humanismo cívico, o tema da fundação ganha notoriedade. Como vimos acima, desde as crônicas medievais, há a preocupação em se estabelecer a origem das cidades, e o caso de Florença é emblemático. A querela característica do Quattrocento, se Florença foi fundado pela Roma imperial ou republicana, adentra no Cinquecento, mas com um diferencial importante. Ao entrar na disputa, Maquiavel não apenas sustenta uma posição minoritária em relação à origem de sua cidade, mas também, e mais importante, desenvolve uma teoria própria da fundação. Para o secretário florentino, é inócuo reconhecer se foi uma república ou um império que fundou Florença se essas diferenças não carregarem consigo consequências para a formação dos costumes e das instituições que sobrevivam ao tempo e cheguem em seu contexto.

\footnotetext{
15 "Posso me lembrar de muitas cidades fortificadas que foram tomadas, os troféus quase incontáveis dos povos vizinhos conquistados por esta cidade, feitos militares egrégios realizados pelo mesmo povo florentino ao sair a campo e regozijar o lançar-se à batalha. Mas agora não é a hora de descrever as muitas guerras e tantos feitos realizados. Isso requereria uma obra própria, e bem extensa, que nós, assim o espero, em algum momento comporemos, e confiaremos às letras e à memória os feitos únicos realizados pelo povo de Florença. No presente texto, referiremos apenas um ou outro exemplo, de modo que a partir deles se possa compreender quão grande foi a virtude desta cidade em todos os outros não citados" (LEONARDO BRUNI ARETINO Laudatio, 2016, § 65).
} 
A dificuldade do sistema teórico advindo das consequências da fundação reside justamente no momento histórico ou imaginado no qual ela ocorre. O modo pelo qual uma cidade é fundada conduz suas instituições fundamentais e condiciona (POCOCK 2003, p. 188), embora não determine, a conservação do regime. A distinção entre a fundação e a conservação se torna evidente (BIGNOTTO 1991, p. 144-146). Por isso, Maquiavel precisa de um modelo, de um quadro teórico e tipológico dos diferentes modos de fundação, do qual sua conservação, ao menos em parte, depende. No texto, é muito claro que "todas as cidades são edificadas ou por homens nativos do lugar onde se edificam ou por forasteiros" (MACHIAVELLI 2006 v. 1, p. 419). O primeiro caso, dos nativos, cujos exemplos são Atenas e Veneza, se contrapõe às fundações realizadas por estrangeiros.

A cidade grega teve Teseu como fundador, mas Veneza não teve ninguém, e nesse ponto surge uma questão fundamental. Maquiavel é taxativo quanto ao fato de que a fundação só pode ser feita por uma única pessoa (BIGNOTTO 1991, p. 134) ${ }^{16}$, mas há uma controvérsia aparente:

A outra, sendo muitos povos reduzidos em certas ilhotas que existiam na ponta do mar Adriático, para fugir daquelas guerras que todo dia ocorriam pela chegada de novos bárbaros à Itália, depois do declínio do Império romano, começaram entre eles, sem qualquer príncipe particular que Ihes ordenasse, a viverem sob aquelas leis que Ihes pareciam aptas à própria manutenção (MACHIAVELLI 2006, v. 1, p. 420).

Esse é o caso de Veneza: não foi ordenada por um líder em particular, por isso, não escolheu seu local de assentamento, mas, apesar disso, teve leis. Sobre as duas características basilares do fundador, eleger o local de edificação e legislar, aquelas terras remotas do Adriático não tiveram escolha. As leis, por seu lado, apenas "pareciam" aos povos ali reunidos pelo medo dos hunos as mais aptas a manter a comunidade, contrariamente de Teseu, que sabia quais eram as leis devidas à aplicação ao povo de Atenas. Esse não é um detalhe de menor significado: Veneza não teve o lugar por escolha nem as leis eram, necessariamente, as mais aptas, apenas pareciam que sim. Se cotejarmos essa passagem com a descrição de História de Florença (2013, $I, 29)$ sobre a origem dessa cidade, fica evidente que a conservação da sereníssima república somente teve sucesso por mero acaso. A fortuna lhe concedeu a oportunidade geográfica de isolamento que Ihe permitiu viver autogovernada por séculos. 
Nessas condições, Veneza vivia em ócio, não havia quem lhe atacasse, "de tal modo que de cada pequeno princípio Ihe podia vir àquela grandeza na qual estão" (MACHIAVELLI 2006, v. 1, p. 421). Na verdade, Veneza passa a ser a expressão máxima do que ocorre com povoamentos de "pequenas partes" (MACHIAVELLI 2006, v. 1, p. 422) quando não encontram seu fundador: não têm, portanto, o maravilhoso momento do encontro do fundador com seu povo, a fim de lhe conferir leis e o lugar de moradia e, por isso, está completamente abandonada à fortuna (MANSFIELD 1979, p. 28). ${ }^{17}$ Ainda que desforme, a cidade, se abandonada à sua própria causa, pode sobreviver.

A virada maquiaveliana na crítica à estabilidade veneziana, caracteristicamente humanista, visto que a sereníssima era elogiada há gerações de florentinos pelas suas instituições (GILBERT 1968), não apenas oportuniza a questão da necessidade do fundador, mas, sobretudo, apresenta um contraexemplo de sua própria teoria. É típico de Maquiavel escolher casos históricos que corroboram e outros que contradizem suas proposições, sempre a fim de concluir por uma vertente. Veneza é uma exceção extremamente atípica, pois conservou-se sem fundador (DOTTI 1979, p. 119). O caso concreto, historicamente determinado, é completamente indiferente às potentes formas organizacionais de cada origem.

$\mathrm{Na}$ sequência, o florentino se dedica às cidades que são fundadas por forasteiros, e novamente apresenta uma bifurcação: ou por homens livres ou por aqueles, à maneira das colônias, que tornam a região dependente (MACHIAVELLI 2006 v. 1, p. 421). Das cidades dependentes emergem novas classificações que, para nosso estudo, não vêm ao caso. Importa é notar que, das alternativas possíveis de fundação - por um homem nativo ou um povo nativo; por um estrangeiro livre ou colonizador -, apenas uma delas, a colonização, oblitera o autogoverno e, portanto, a liberdade. Essa tipologia pode ser muito enganosa porquanto se saiba que os casos mais correntes são aqueles de expansão e colonização. " $E$, por não ter essas cidades a sua origem livre, raras vezes ocorre que façam empreendimentos grandiosos, e pode-se numerar nesses casos os chefes dos Estados" (MACHIAVELLI 2006 v. 1, p. 421).

Em paralelo a essa tipologia, Maquiavel atribui uma classificação das cidades livres, aquelas efetivamente fundadas por um homem ou pelo próprio povo, respectivamente, nos exemplos anteriores, Atenas e Veneza. Essa nova maneira de compreender as

Esse ponto da argumentação suscitou diferentes interpretações, como a necessidade do uso da força e do medo na fundação bem-ordenada de qualquer cidade, ou da espontaneidade da origem dos agremiados humanos. Sobre isso, conferir Ion (2006) e Morfino (2015). 
cidades livres deve ser entendida pela primeira vez na qual a cidade é edificada, a fundação propriamente dita, cujo exemplo máximo é Moisés, ou se é reordenada, isto é, "são edificadas de novo, como fez Enéas" (MACHIAVELLI 2006 v.1, p. 422) ${ }^{18} \mathrm{com}$ Roma. Isso sugere que há uma distinção de fundo teórico entre a fundação de uma cidade e a sua reordenação.

Moisés, depois de libertar seu povo e vagar com ele errante no deserto, escolheu Canaã e atribui-Ihe as ordens fundamentais. Ainda que analiticamente essas duas ações sejam distintas - a da fundação original e a da reordenação - livres ou subjugadas, o fato é que as características fundamentais de cada uma delas não possuem distinções significativas. Ambas promovem novas ordens e se assentam em um lugar, ou por escolha, ou por necessidade (MACHIAVELLI 2006 v. 1, p. 422). De toda essa tipologia, o caso mais sofisticado e controvertido, seja porque rompe com a tradição florentina ou porque insere elementos populares, ou mesmo pela constante dúvida que paira sobre a veracidade dos fatos, é Roma. Todavia, a disputa que nos interessa, a historiográfica, é sobre Florença. No que concerne à sua cidade, Maquiavel está em direta rota de coalizão com o humanismo cívico.

Estabelecido o quadro tipológico das fundações, cabe, então, compreender em qual situação Florença se encaixa e quais as consequências disso. Dentre as fundações promovidas por forasteiros, Florença é o exemplo escolhido de colônia nos Discorsi. No entanto, o que verdadeiramente chama a atenção é que, das quatro maneiras pelas quais surgem as cidades acima mencionadas, um caso é o mais comum.

O segundo caso, quando por pessoas forasteiras é edificada uma cidade, nasce ou de homens livres ou que dependem de outros: como são as colônias mandadas ou por uma república ou por um príncipe para tomar as terras dos habitantes ou para defender aquele país que (de novo adquirido) deseja seguramente e sem despesa se manter. Dessas cidades o povo romano edificou muitas e por todo seu império (MACHIAVELLI 2006, v. 1, p. 421).

Do ponto de vista do povo edificado, não importa, caso seja uma ação colonizadora, se a empreitada foi realizada por um príncipe/império ou por uma república (FALCÃO 2019). Esse ponto é demasiadamente importante, não porque finda com a querela humanista, mas porque a coloca em segundo plano. Não é a fundação realizada por uma república o que garante a liberdade da cidade fundada, como afirma o exemplo 
romano. É evidente que a discordância é, dentre outros, com Bruni. Ao afirmar a original liberdade florentina a partir da fundação pela Roma republicana, Bruni argumenta que a linha de consecução entre Roma e Florença é mantida por um prolongamento arquitetônico, dos valores cívicos e da liberdade. Maquiavel não compartilha dessa suposição: por mais livre que seja uma cidade, ela sempre pode colonizar outra e, assim, subjugá-la. Aliás, é essa a regra geral das cidades livres (MACHIAVELLI Discorsi, 2006 , v. 2, II, 32). ${ }^{19}$

A fundação de Florença é minimizada por ter sido feita a partir da obra da colonização romana, afinal a colonização é um modo de distribuir os homens adequadamente entre os territórios e engrandecer as regiões desérticas (MACHIAVELLI Istorie Fiorentine, 2013, II, 1). Ao tangenciar um elogio colonizador, com exemplos não apenas romanos, mas também árabes sobre Pisa e Gênova, Maquiavel promove mais um lance teórico e uma ruptura com o humanismo. Se a fundação via colonização é de fato um problema, não é o pior deles. Por isso, amenizar o ato colonizador fundacional transfere, ao menos em parte, a responsabilidade dos feitos da cidade para seus cidadãos, tornando-a mais autônoma em relação à origem do que defendiam Salutati, Bruni e Bracciolini. "Naqueles tempos antigos, então, em virtude dessas colônias, ou elas nasciam como cidades novas, ou, já existentes, cresciam; das quais foi a cidade de Florença, que teve de Fiesole o princípio e das colônias o crescimento" (MACHIAVELLI 2013, p. 497).

Fiesole já era uma cidade estabelecida quando o território no qual se instalaria Florença ainda era desocupado, mas, entre as montanhas toscanas e o rio Arno, havia um lugar propício para o assentamento, ainda que provisório, dos mercadores que entravam e saíam de lá. "Esses mercadores acredito que foram a causa das primeiras edificações que naqueles lugares se fizeram, os mercadores desejavam ter comodidade para alocar as suas mercadorias que, com o tempo, transformaram em edificações firmes" (MACHIAVELLI 2013, p. 497). A não ser pelo medo que movia os fugitivos dos hunos para o que viria a ser Veneza, as primeiras edificações da região florentina não tinham nada de diferente da sereníssima, o que é, em si mesmo, no universo maquiaveliano, algo bastante incomum.

\footnotetext{
19 A crítica de Maquiavel a Bruni e, em geral, às histórias humanistas reside no fato de que elas teriam sido compostas para o louvor de homens poderosos, mas a própria História de Florença fora feita sob encomenda de Clemente VII, papa Médici (cf. RIDOLFI 2003, p. 182-183). O tema é bastante sensível e necessitaria de uma pesquisa à parte, mas destaque-se que sua crítica ao humanismo promove um verdadeiro marco na concepção de que, ao fim, toda história é produzida em razão de posições políticas inseridas no contexto em que é escrita. Cf. Maquiavel (2013, p. 468) e Sasso (1993 v. 1, p. 170-173). Sobre esse ponto, conferir especialmente o contraste entre Maquiavel e Bruni sobre a historiografia da cidade de Florença e o uso político dela em Hankins (2017).
} 
Percebe-se aqui a distinção analítica acima aludida sobre a fundação e a reedificação, mas a sequência também deixa clara a pouca relevância da separação conceitual: "e, depois, quando os romanos venceram os cartagineses, fizeram a Itália segura das guerras externas, multiplicaram-se em grande número as edificações" (MACHIAVELLI 2013, p. 497). Roma, diferentemente de Esparta e de Atenas (POCOCK 2003, p. 197), não foi fundada por um único homem, mas por um conjunto de ações, da migração de Enéas à criação do Tribunato da Plebe, de tal modo que a continuidade da edificação foi-lhe favorável pois a fortuna assim o permitiu. Todavia, o ímpeto expansionista dessa cidade ocorreu após a queda de Cartago. O que Bruni retirou de Salústio, a vitória externa que levou à decadência interna e moral de Roma, é, para Maquiavel, algo nada relevante, porquanto se tenha claro que o declínio da virtude romana não implica a qualidade da colonização, que é algo sempre impositivo e jamais livre. O que importa para Maquiavel é que o expansionismo romano se fez mais eficaz e robusto apenas quando Cartago caiu, pois, então, a colonização peninsular se tornou viável.

Florença começou como Veneza, um punhado de migrantes que não despertava inicialmente qualquer interesse em ninguém em estabelecer assentamento definitivo, e depois se tornou colônia de Roma. Primeiramente as tropas de Sila, depois as do triunvirato, após o assassinato de César, incumbiram-se do controle de Fiesole e, com o aumento dessa, edificou-se Florença. O texto maquiaveliano não é claro quanto ao momento da expansão de Fiesole ao ponto de se saber se se tratava da república ou do império de Roma, o que, na verdade, é algo absolutamente compreensível, pois é indiferente, já que a empreitada é colonizadora. É importante notar, porém, que esse relato não é exatamente distinto do de Bruni na História, mas sim do da Laudatio. Portanto, a crítica de Maquiavel ao seu antecessor na chancelaria não remonta à fundação, mas ao entendimento do que isso significa. Se Salutati e Bruni exaltavam a fundação de Florença pelo ato da república romana e, com isso, inseriram uma querela historiográfica no humanismo sobre as provas e contraprovas materiais e textuais, Maquiavel responde simplesmente que isso é irrelevante, uma vez que a colonização, por uma república ou por um império, não traz diferenças substanciais para quem é colonizado ${ }^{20}$.

Em suma, para Maquiavel, Florença não foi fundada pela República Romana, mas edificada uma segunda vez em algum momento entre as guerras de Sila contra Mario

\footnotetext{
${ }^{20}$ De fato, a análise poderia se estender à diferença de concepção sobre a ação fundadora da república segundo Bruni e a ocupação exploratória de Maquiavel, na qual o primeiro supõe uma continuidade de um povo para com o outro e o segundo uma distinção de fundo, mas adentrar nesses temas fugiria do escopo de um artigo.
} 
e de César contra Pompeo, isto é, entre os últimos períodos da expansão republicana e os primeiros do império, concordando, portanto com a História de Bruni. Talvez não seja uma posição inadvertida do secretário florentino manter em suspenso o momento exato da fundação de sua cidade. É possível que esse seja um modo elegante de escapar da querela, ainda mais se se reconhece que é inócuo ser fundado por uma república ou império quando o objetivo é colonizar. A ambivalência dessa posição pode levar um leitor familiarizado com o discurso humanista a não ser confrontado, mas a recusa em ratificar a fundação pela república não é menos importante.

O grande rompimento teórico e historiográfico de Maquiavel não reside em apresentar novas e robustas afirmações sobre a fundação de Florença, mas em declinar da importância dela quando o objetivo é meramente colonizar. Em si mesmo, isso descredencia que seja Florença livre porque é oriunda da República Romana e, além disso, ao diluir a edificação da cidade no tempo, pela ocupação de comerciantes e depois pela militar, transfere a história da cidade para seu próprio povo. Tudo isso só é possível porque há um substrato teórico de fundo que arregimenta o sentido da fundação, e nele, pelo caminho mais inesperado, chega-se a conclusões muito próximas das do humanismo. Florença se assemelha a Roma não porque herdou sua liberdade e virtude republicanas, mas porque foi edificada paulatinamente pela constrição da necessidade ${ }^{21}$.

Porque os homens não se mantêm nunca na dificuldade se uma necessidade não os faz se manter, de tal modo que, embora o medo das guerras os constranja a habitar voluntariamente os lugares fortificados e ásperos, terminada a guerra, são chamados à comodidade e mais voluntariamente ainda habitam os lugares domesticados e fáceis (MACHIAVELLI 2013, p. 497).

Mercadores e soldados foram forçados pela necessidade a edificarem e desenvolverem aquele lugar que ganharia o nome de Florença, do mesmo modo que Enéas foi forçado a habitar o lugar que se chamaria Roma ao fugir de Troia. A necessidade pariu ambas as cidades, e isso, contrariamente ao humanismo cívico, nada tem que ver com sua liberdade ou virtude, menos ainda com a república que cada uma se tornaria.

${ }^{21}$ Nesse ponto, a perspectiva prudencial do pensamento histórico de Maquiavel salta aos olhos. A distinção das causas originais não implica que os resultados sejam, necessariamente, diferentes, o que significa que qualquer cidade fundada no tempo possui uma potência maior, porque prudencialmente aprende com a história a ser livre. Cf. CHARBEL 2010. Ainda sobre o emprego de Roma como modelo histórico em consecução de poder ser reproduzido naquele presente, cf. POCOCK 2010. 


\section{Conclusāo}

Salutati, Bruni e Maquiavel, como foi mostrado acima, empreendem uma verdadeira ruptura com a crônica medieval, aqui representada pela referência central da historiografia florentina, Villani. O fato, em si, daquilo que modificam é a interpretação da origem de Florença, particularmente em Salutati e no jovem Bruni. Na História de Bruni e em Maquiavel, ocorre o questionamento dessa origem republicana e, nesse último, a verdadeira importância da cidade ter sido fundada por uma república é desprestigiada como tema inútil. Uma vez que os objetivos fundacionais, argumenta Maquiavel contra os humanistas, não são outros que não a colonização, uma república não é menos perniciosa ou mais livre do que impérios e principados. É possível rastrear o discurso humanista pelo menos até meados do século $X X$, no qual a qualidade do agente fundador/ colonizador implica a qualidade da cidade fundada. No entanto, essa crítica somente se mostra factível porquanto se compreenda que Maquiavel inaugura no tema da fundação uma verdadeira abordagem teórica que transpassa os limites das comprovações históricas.

Não obstante essa ruptura, é preciso chamar a atenção para um último ponto. Salutati, Bruni e Maquiavel recorrem, diferentemente de Villani, à mesma fonte, Salústio; ainda que os três igualmente recorram a Villani, cada qual a seu modo. O historiador de Roma oportuniza a esses três pensadores a avaliação sobre as causas das guerras itálicas, a necessidade que imperou entre comerciantes fiesolanos e militares romanos e, sobretudo, a origem de uma fundação ou reordenação oriunda de um centro de poder grandioso. Todos esses termos são caracteristicamente renascentistas, o que leva a reconhecer, no caso concreto desse estudo, a importância paradigmática do retorno aos antigos e, simultaneamente, a lê-los criticamente.

\section{REFERÊNCIAS}

ARISTIDES, Elio. "Panatenaico". In: ARISTIDES, Elio. Discursos I. Introducción, traducción y notas de Fernando Gascó y Antonio Ramirez de Verger. Madrid: Editorial Gredos, 1987. p. 113-254.

BARON, H. From Petrarch to Leonardo Bruni: Studies in Humanistic and Political Literature. Chicago: University of Chicago Press, 1968. 
BARON, H. The Crisis of the Early Italian Renaissance. Princeton: Princeton University Press, 1955.

BERNARD-PRADELLE, Laurence. L'Influence de la Seconde Sophistique sur la Laudatio Florentinae urbis de Leonardo Bruni. Rhetorica: A Journal of the History of Rhetoric, v. 18 , n. 4 , p. $355-387,2000$.

BIGNOTTO, Newton. Maquiavel republicano. São Paulo: Loyola, 1991.

BIGNOTTO, Newton. Origens do republicanismo moderno. Belo Horizonte: Editora UFMG, 2001.

CHARBEL, Felipe. Timoneiros: retórica, prudência e história em Maquiavel e Guicciardini. Campinas: EdUnicamp, 2010.

DOTTI, Ugo. Niccolò Machiavelli: la fenomenologia del potere. Milano: Feltrinelli Editore, 1979.

FALCÃO, Luís. Governo misto ou república popular: a república adaptativa nos Discorsi de Maquiavel. In: ADVERSE, Helton e PANCERA, Carlo Gabriel (org.). As faces de Maquiavel: história, república, corrupção. Belo Horizonte: D'Plácido, 2019. p. 77-100.

FUBINI, R. Osservazioni sugli Historiarum Florentini Populi Libri XII di Leonardo Bruni. In: SESTAN, Ernesto (org.). Studi di Storia Medievale e Moderna per Ernesto Sestan. v. 1, Firenze: Leo S Olschki Editore, 1980. p. 403-448.

FUMAROLLI, M. L'Âge de l'éloquence. Rhétorique et «res literaria» de la Renaissance au seuil de l'époque classique. Paris : Librairie Droz S.A., 1994.

GALAND-HALLYN, P. La rhétorique en Italie à la fin du Quattrocento (1475-1500). In: FUMAROLI, M. (dir.). Histoire de la rhétorique dans I'Europe moderne 1450-1950. Paris: Presses Universitaires de France, 1999. p. 131-190.

GARIN, E. Moyen Âge et Renaissance. Paris, 1969.

GILBERT, Felix. "The Venetian constitution in Florentine Political Thought". In: RUBINSTEIN, Nicolai (ed.). Florentine Studies: politics and society in renaissance Florence. London: Faber and Faber, 1968. p. 115-170. 
HANKINS, J. Coluccio Salutati e Leonardo Bruni. In: CILIBERTO, M. (org.). Enciclopedia Italiana. Ottava appendice. Il contributo italiano alla storia del pensiero. Filosofia, Roma 2012. p. 85-94.

HANKINS, J. Leonardo Bruni and Machiavelli on the lessons of Florentine history. In: FRANCESCONI, Giampaolo; MIGLIO, Massimo (ed.). Le cronache volgare in Italia. Roma: Istituto Palazzo Borromini, 2017. p. 373-396

HANKINS, J. The 'Baron Thesis' after Forty Years and Some Recent Studies of Leonardo Bruni. Journal of the History of Ideas, v. 56, n. 2, p. 309-338, 1995.

ION, Cristina. Conquérir, fonder, se maintenir. In: GAILLE-NIKODIMOV, Marie; MÉNISSIER, Thierry (dir.). Lectures de Machiavel. Paris: Ellipses, 2006. p. 92-128.

KLEIN, Francesca. Considerazioni sull'ideologia della città di Firenze tra Trecento e Quattrocento. Giovanni Villani - Leonardo Bruni. Richerche historiche, n. 10, p. 311-336, 1980.

KRISTELLER, P. O. La diffusione in Europa dell'Umanesimo italiano. Italica, XXXIX, p. $1-20,1962$.

LEONARDO BRUNI ARETINO. Elogio da cidade de Florença. Tradução e análise Fabrina Magalhães Pinto e Alexander Viana. Revista Morus, Campinas, v. 11. n. 2, p. 245-335, 2016. Disponível em: http://www.revistamorus.com.br/index.php/morus/ article/view/292. Acesso em: 30 abr. 2019.

LEONARDO BRUNI ARETINO. Historiarum florentini populi libri XII e Rerum suo tempore gestarum commentarius. Edited by Emilio Santini and Carmine Di Pierro. [S. I.]: Città di Castello, 1926. (Rerum Italicarum Scriptores, 19.3).

LEONARDO BRUNI ARETINO. History of the Florentine People. Edited and translated by James Hankins. Cambridge: I Tatti Renaissance Library\Harvard University Press, 2001. v. 1.

LEONARDO BRUNI ARETINO. History of the Florentine People. Edited and translated by James Hankins. Cambridge: Harvard University Press, 2004. v. 2.

LEONARDO BRUNI ARETINO. History fo the Florentine people. Cambridge: Harvard University Press, 2007. Trad. James Hankins. v. 2. 
LEONARDO BRUNI ARETINO. Laudatio Florentinae Urbis. In: BARON, H. From Petrarch to Leonardo Bruni: Studies in Humanistic and Political Literature. Chicago: University of Chicago Press, 1968. p. 232-263.

LEONARDO BRUNI ARETINO. Laudatio Florentinae Urbis. In: BERNARD-PRADELLE, Laurence (ed.). Histoire, Éloquence et Poésie à Florence au début du Quattrocento. Textes choisis, édites et traduits par Laurence Bernard-Pradelle. Paris: Honoré Champion, 2008. p. 205-301.

LEONARDO BRUNI ARETINO. Laudatio Florentinae Urbis. In: VITI, Paolo. Opere Letterarie e Politiche di Leonardo Bruni. Torino: Unione Tipografica Editrice Torinese, 1996. p. 568-647.

LUIZ, Vânia Vidal. Fórum de verdade e ficção: a crônica de Giovanni Villani na Florença Medieval. 2014. Dissertação (História) - Programa de Pós-Graduação em História Social, Universidade Federal do Estado do Rio de Janeiro, Rio de Janeiro, 2014.

MACHIAVELLI, Niccolò. Discorsi sopra la prima deca di Tito Livio, Dell'arte della guerra e altre opere. A cura di R. Rinaldi. Torino: UTET, 2006. 2 v.

MACHIAVELLI, Niccolò. Istorie Fiorentine. In: MACHIAVELLI, Niccolò. Tutte le opere storiche, politiche e letterarie. A cura de A. Capata. Roma: Newton Compton, 2013. p. 467-694.

MANSFIELD, Harvey Claflin. Maquiavelo y los principios de la política moderna: un estudio de los Discursos sobre Tito Livio. Traducion de Stella Mastrangelo. México D. F.: Fondo de Cultura Económica, 1979.

MOLINIÉ, G. Dictionaire de Rhétorique. Paris: Librairie Générale Française, 1992.

MORFINO, Vittorio. The five theses of Machiavelli's "philosophy". In: LUCCHESE, F. del, FROSINI, F. e MORFINO, V. (ed.). The radical Machiavelli: politics, philosophy and language. Boston: Brill, 2015. p. 144-173.

MURPHY, J. La elocuencia en el renacimiento: Estudios sobre la teoría y la práctica de la retórica renacentista. Visor Libros, 1998.

MURPHY, J. La retorica nel Medioevo. Editora : Liguori, 1983.

NAJEMY, J. M. Storia di Firenze 1200-1575. Torino: Giulio Einaudi editore, 2014. 
PERELMAN, Chaim. Traité de I'Argumentation: la Nouvelle Rhetoric. Paris: Bruxelles: Universite de Bruxelles, 1976.

PINTO, Fabrina M. "Retórica e política no Humanismo Renascentista: Reflexões sobre a laudatio florentinae urbis, de Leonardo Bruni" In: RAGAZZI, A; MENESES, P.; QUIRÍACO, T. (org.). Ensaios Interdisdiplinares sobre o Renascimento italiano. São Paulo: Editora Unifesp, 2017. p. 163-187.

PIRES, Francisco Murari. Modernidades Tucidideanas: Ktema es Aei. São Paulo: Editora da Universidade de São Paulo: Fapesp, 2007.

POCOCK, J. G. A. Rome: the republic as ideal and history. In: NAJEMT, John (ed.). Cambridge Companion to Machiavelli. Cambridge: Cambridge University Press, 2010. p. $144-156$.

POCOCK, J. G. A. The Machiavellian moment: Florentine political thought and the republican Atlantic tradition. Princeton: Princeton University Press, 2003.

QUINTILIANO. Institutio oratoria. Books I-III. Translate by H. E. Butler. London Harvard University Press, 1920. Loeb Classical Library.

RIDOLFI, Roberto. Biografia de Nicolau Maquiavel. Tradução de Nelson Canabarro. São Paulo: Musa, 2003.

SALLUST. The war of Catiline. The war of Jugurtha. Edited and translation by John Ramsay. Boston: Harvard University Press, 2013.

SALÚSTIO. A conjuração de Catilina. In: SÊNECA; SALÚSTIO. Tratado sobre a clemência. A conjuração de Catilina. A guerra de Jugurta. Tradução de Antonio da Silveira Mendonça. Petrópolis: Vozes, 1990. p. 95-134. Coleção clássicos do pensamento político.

SALUTATI, Coluccio. "Invective Against A. Loschi". In: BALDASSARI, S. Coluccio Salutati. Political Writings. London: The I Tatti Renaissance Harvard University Press, 2014. p. 144-167.

SASSO, Gennaro. Niccolò Machiavelli, vol. 1: Il pensiero politico; vol. 2: La storiografia. Bologna: Il Mulino, 1993. 2 v. 
SKINNER, Quentin. As fundações do pensamento político moderno. Tradução de Renato Janine Ribeiro. São Paulo: Companhia das Letras, 1996.

VASOLI. Considerazioni sulla Laudatio Urbis Florentinae di Leonardo Bruni. Em Estrato dall'Annuario 1961-1962 del Liceo Ginnasio Statale F. Petrarca di Arezzo, MISC. XXXV I. Firenze: Istituto Nazionale di Studi sul Rinascimento.

VILLANI, Giovanni. Nuova Cronica. In: PORTA, G. Nuova Cronica, di Giovanni Villani. Ed. Giuseppe Porta. Biblioteca di scrittori italiani. Parma: Fondazione Pietro Bembo / Ugo Guanda editore, 1991.

VITI, Paolo. Laudatio florentine urbis (Elogio dela città di Firenze). In: VITI, Paolo. Opere letterarie e politiche di Leonardo Bruni. Torino: Unione Tipografico-Editrice Torinese, 1996. p. 568-647.

WILCOX, D. J. The Development of Florentine Humanist Historiography in the Fifteenth Century. Cambridge: Harvard University Press, 1969.

WITT, G. The Origins of Humanism from Lovato to Bruni. Leiden: Boston-Cologne, 2000.

\section{INFORMAÇŌES ADICIONAIS}

\section{BIOGRAFIA PROFISSIONAL}

Fabrina Magalhães Pinto é doutora em História Social da Cultura pela Pontifícia Universidade Católica do Rio de Janeiro (PUC-Rio), 2006, Pós-Doutora em Filosofia pela Pontifícia Universidade Católica do Rio de Janeiro (PUC-Rio), 2010 e Pós-Doutora em Filosofia pela Universidade Federal de Minas Gerais(UFMG), 2016, professora associada de História da Universidade Federal Fluminense (UFF) no Pólo Universitário de Campos dos Goytacazes (PUCG) e coordenadora do Laboratório de Estudos Republicanos (LER) na mesma instituição. Organizou, com Danilo Marcondes, a edição especial sobre da revista O que nos faz pensar? (2010); com Flavia Benevenuto, o dossiê temático Renascimento Italiano, pela revista Crítica Histórica (2015), e o livro Filosofia, Política e Cosmologia: ensaios sobre o renascimento italiano (EdUFABC, 2017). Autora da apresentação do Elogio da Loucura de Erasmo de Roterdã (Edipro, 2015). 
Luís Falcão é doutor em Ciência Política pelo Instituto de Estudos Sociais e Políticos (IESP) da Universidade do Estado do Rio de Janeiro (UERJ),(2015), professor adjunto de Ciência Política e do Programa de Pós-Graduação em Ciência Política da Universidade Federal Fluminense (UFF), onde coordena o Laboratório de Estudos Republicanos (LER). Autor de Maquiavel, Montesquieu e Madison: uma tradição republicana em duas perspectivas (Azougue, 2013), Algernon Sidney: um pensador republicano do século XVII (EdUFF, 2019), Algernon Sidney between modern natural rights and Machiavellian republicanism (Cambridge Scholars Publishing, 2020), Ensaios Republicanos (Appris, 2021) e O pensamento político de James Harrington: republicanismo, maquiavelismo e inovação (EdUFABC, no prelo).

\section{ENDEREÇO PARA CORRESPONDÊNCIA}

Luís Falcão. Rua Marcos Waldemar, sem número, Bloco O, Sala 220, São Domingos, Niterói, Rio de Janeiro, Brasil. CEP: 24210-201.

\section{FINANCIAMENTO}

Não se aplica.

\section{CONTRIBUIĊĀO DE AUTORIA CRediT}

Conceituação: PINTO, Fabrina Magalhães; FALCÃO, Luís.

Investigação: PINTO, Fabrina Magalhães; FALCÃO, Luís.

Escrita - rascunho original: PINTO, Fabrina Magalhães; FALCÃO, Luís.

Escrita - revisão e edição da versão final: PINTO, Fabrina Magalhães; FALCÃO, Luís.

\section{CONFLITO DE INTERESSES}

Nenhum conflito de interesse declarado.

\section{APROVAÇĀO EM COMITÊ DE ÉTICA}

Não se aplica.

\section{MODALIDADE DE AVALIAÇĀO}

Duplo-cega por pares.

\section{PUBLICAÇĀO PRÉVIA / PRIOR PUBLICATION / PUBLICACIÓN PREVIA}

Remover se não se aplicar 


\section{EDITORES RESPONSÁVEIS}

Temístocles Cezar - Editor-Chefe

\section{DIREITOS AUTORAIS}

Copyright (c) 2020 História da Historiografia: International Journal of Theory and History of Historiography.

\section{LICENÇA}

Este é um artigo distribuído em Acesso Aberto sob os termos da Licença Creative Commons Atribuição-NãoComercial-SemDerivações 4.0 International.

HIISTÓRICO DE AVALIAÇĀO

Recebido em: 15 de maio 2020.

Alterado em: 10 de setembro de 2020.

Alterado em: 26 de outubro de 2020.

Aprovado em: 22 de dezembro de 2020. 